UDK 528.932

\title{
SELECTING THE DISTINCTIVE POINTS OF THE LAND SURFACE FOR MODELLING THE RELIEF
}

\author{
Žilvinas STANKEVIČIUS \\ Department of Geodesy and Cadastre, Vilnius Gediminas Technical University, \\ Sauletekio al. 11, LT-10223 Vilnius, Lithuania \\ E-mail: z.stankevicius@gis-centras.lt
}

Received 24 July 2014; accepted 9 March 2015

\begin{abstract}
In order to prepare a project on rebuilding an old or constructing a new road and work drawings, knowledge of the present local objects is necessary. The performance of road construction or reconstruction is aimed at using digital models for the relief and at helping with more precise design, a decrease in the environmental impact and work optimization. Digital local models are most frequently prepared according to data on laser scanning. Redundant metering data on height points have been accumulated using a laser scanning technique. Because of redundant height points, for automatically creating and designing a model for the relief, computer resources must be irrationally used under slower modelling processes. The methodology provided in the article could be suitable for eliminating redundant points of height metering keeping them in distinctive relief positions. According to the proposed methodology, an algorithm has been created and used in the experimental theory for eliminating redundant points. In order to check the correctness of algorithm performance, a project on road reconstruction has been simulated and the volumes of land works using relief models created in the event of the full and filtrated array of height points have been compared.
\end{abstract}

Keywords: land surface scanning, relief modelling, filtration of laser scanning points.

\section{Introduction}

In order to prepare a project on rebuilding an old or constructing a new road and work drawings, knowledge of the present local objects is necessary. To get the following information, metering the position of the object must be carried out in the location and digital topographical plans have to be prepared. The performance of road construction or reconstruction is aimed at using digital relief models and at helping with more precise design and a decrease in the environmental impact (Abdullah et al. 2014; Russell et al. 2010). In addition, relief models can be used for the optimization of road reconstruction works (Marzouk et al. 2014).

At the moment, various equipment are used for determining the objects present in the construction site planned in the three-dimensional sphere: electronic geodesic devices for metering corners and distances, an unmanned aircraft with photo cameras, mobile systems for optical metering (laser scanners) and panoramic ground photogrammetric systems. When the measured data are planned to be used for creating drawings of old road reconstruction or building a new one, information on absolute heights, i.e. data on the surface relief, is very important. Absolute heights have to be included in the project on road design together with an array of the points having coordinates $x, y, z$ (Abdullah et al. 2014). The extent of the array should be appropriate for creating the qualitative surface and, at the same time, should not be redundant.

When height is measured employing traditional methods, i.e. using electronic tachometers, the minimum quantity of information on height is collected. According to GKTR 2.08.01.:2000 "Geodesic Investigations into Construction Engineering", the determined height should be measured at a distance of at least $15 \mathrm{~m}$. Such density of the points at the location of the relief is not appropriate for creating the qualitative relief model and calculating a precise volume of land work (Stankevičius et al. 2009).

Priority is more often given to the methods of laser scanning. The dense array of three-dimensional 
points (3D) has been created employing the method of laser scanning. The array includes all measurements of the objects in the field of view of the scanner. The application of various filtering methods assists in eliminating the measurements of the non-land surface from the array. However, the chosen points of the land are of redundant nature, i.e. the points densely cover flat surfaces and surface edges. When creating surface models (TIN), redundant points become nodal points of the surface network and the elements of an optional network of the surface (triangles) are created. The redundant elements of the surface model slacken the performance of automatic design systems (for instance, AutoCAD Civil, Microstation InRoad).

The article describes the methodology created for slackening the array of the point in order to protect distinctive surface points. The methodology has been tested using the created calculation algorithm and scientific software. The efficiency of the methodology has been checked calculating changes in land volume between the primary and filtrated surface of the tested territory.

\section{Problem determination}

The problem to be solved covers slackening the array of $3 \mathrm{D}$ points and leaving distinctive surface points retaining the complexity of the surface. Distinctive surface points are those located in the sections of the changed surface and include the edges of slopes and smaller relief objects.

In order to retain all points defining changes in the surface, it is necessary to select redundant points only, i.e. the points in the chosen tolerance zone of the same plane.

When applying the principle of thinning by a regular network, the primary array of surface points will be redistributed to the array of the central points of network elements. Such calculations cannot select distinctive surface points.

The methods applying the analysis of differences in distances and height between the investigated and surrounding points are suitable for selecting distinctive points. Such methods are used for statistical evaluation if the tested point can be considered in the range of tolerance accepted in the plane. Such techniques can be conditionally divided into the methods that directly use the parameters of the tested point and surrounding points, apply the surface to the surrounding points and evaluate the parameters of the surrounding points and applied surface (Clément et al. 2009; Gomes-Pereira et al. 1999).
In order to perform a procedure for selecting distinctive points, developing analysis algorithm for the surrounding points is not sufficient. In addition, one will need employing an algorithm that would evaluate the analyzed results of the vicinity of the point, selecting the candidates of the points and iterations of calculations as well as applying the scope of vicinity. According to the review of the previous investigations, the authors of the publications have created various algorithms and used different methods (Brügelmann 2000; Briese 2004; Kraus et al. 2001; Wang et al. 2001).

An algorithm for the filtration of laser scanning measurements (points) proposed in the article is based on the fitting of local planes. The novelty of the technology analysed in the article is related to the practical application of the proposed technology during the preparation of the road project and a big opportunity applying the algorithm suggested in various software.

Some manufacturers of commercial software have installed filtration functions of redundant points, for instance, the users of Microstation software can acquire TerraSolid addition. However, in practice, the experts preparing topographical plans and designing roads do not use this specific software. An efficient filtration algorithm proposed in the article is topical and can be installed in any software.

\section{Algorithm description}

The first step is to perform a test on applying the plane at all points. The maximum possible (marginal) size of the extent of vicinity and the minimum possible size of an error of applying the plane is used. The points approximate to the local plane are eliminated (according to the smallest average square-error, rms). A set of points-candidates of the relief model are combined from the points left. The algorithm is realised modifying the previous algorithm found by the author (Stankevičius 2011).

With reference to the least square method, $z=$ $a x+b y+c$ is applied for certain data amount thus assuming that inaccuracies are distributed in direction $z$ for the set surface fitting points. The implemented method is most suitable for orthogonal data, i.e. the one shown in orthographical projection.

As for the algorithm, when using the eigenvector calculation method, perpendiculars are minimized from the point to the plane, whereas non-vertical distances - from the point towards the surface. $a x+b y+$ $c z+d=0$ is applied based on restriction $a^{2}+b^{2}+c^{2}=1$ 
and the optimum evaluation of the plane is obtained and applied if the errors of surface fitting in the set of points are situated in the direction perpendicular to the fitted plane. A more detailed description of the composed algorithm is provided in the previously published article of the author (Stankevičius 2011).

The plane is defined as follows:

$$
a x+b y+c z=d .
$$

The distance of the point from the plane (1) $\mathrm{Ri}$ is

$$
r_{i}=a x_{i}+b y_{i}+c z_{i}-d .
$$

Assuming it is a normalized plane, i.e.

$$
\begin{gathered}
a^{2}+b^{2}+c^{2}=1 ; \\
r_{i}=\left(a x_{i}+b y_{i}+c z_{i}-d\right) / \operatorname{sqrt}\left(a^{2}+b^{2}+c^{2}\right) .
\end{gathered}
$$

In order to define the least square plane, it will be assumed that the sum of the points of a set (coordinates $x_{i}, y_{i}, z_{i}$ ) is $n$; the set of the points aims to be minimized as $Q$ :

$$
Q=\sum_{i=1} r_{i}^{2}
$$

By applying (2)

$$
Q=\sum_{i=1}^{n}\left(a x_{i}+b y_{i}+c z_{i}-d\right)^{2} .
$$

Partial fluxions based on (5)

$$
\begin{aligned}
& \partial Q / \partial a=\sum_{i=1}^{n} 2 x_{i}\left(a x_{i}+b y_{i}+c z_{i}-d\right)=0, \\
& \partial Q / \partial b=\sum_{i=1}^{n} 2 y_{i}\left(a x_{i}+b y_{i}+c z_{i}-d\right)=0, \\
& \partial Q / \partial c=\sum_{i=1}^{n} 2 z_{i}\left(a x_{i}+b y_{i}+c z_{i}-d\right)=0, \\
& \partial Q / \partial d=\sum_{i=1}^{n}-2\left(a x_{i}+b y_{i}+c z_{i}-d\right)=0 .
\end{aligned}
$$

Equation (9) can be rewritten as

$$
d=a x_{0}+b y_{0}+c z_{0},
$$

where $x_{0}=\sum_{i=1}^{n} x_{i} / n ; y_{0}=\sum_{i=1}^{n} y_{i} / n ; z_{0}=\sum_{i=1}^{n} z_{i} / n$.

Equation (10) shows that the best suitable plane for a set of the $3 \mathrm{D}$ point passes through the centre of masses. By subtracting the mass centre from each point and placing into (6-8), we get a set of equations that can be formulated as follows:

$$
W P=0,
$$

where

$$
\begin{gathered}
W=\left(\begin{array}{ccc}
\sum_{i=1}^{n}\left(x_{i}-x_{0}\right)^{2} & \sum_{i=1}^{n}\left(x_{i}-x_{0}\right)\left(y-y_{0}\right) & \sum_{i=1}^{n}\left(x_{i}-x_{0}\right)\left(z-z_{0}\right) \\
\sum_{i=1}^{n}\left(x_{i}-x_{0}\right)\left(y-y_{0}\right) & \sum_{i=1}^{n}\left(y_{i}-y_{0}\right)^{2} & \sum_{i=1}^{n}\left(y_{i}-y_{0}\right)\left(z-z_{0}\right) \\
\sum_{i=1}^{n}\left(x_{i}-x_{0}\right)\left(z-z_{0}\right) & \sum_{i=1}^{n}\left(y_{i}-y_{0}\right)\left(z-z_{0}\right) & \sum_{i=1}^{n}\left(z_{i}-z_{0}\right)^{2}
\end{array}\right) ; \\
P=\left(\begin{array}{l}
a \\
b \\
c
\end{array}\right) .
\end{gathered}
$$

In order to obtain the least square plane, solving equation (11) is necessary. Equation (11) can have solution $a=b=c=0$ that is avoided by placing the following condition in addition to the coefficients of the plain:

$$
a^{2}+b^{2}+c^{2}=1
$$

Condition (12) points to a problem of calculating the eigenvalue when solving (11), i.e.

$$
W P=V E,
$$

where $V$ - eigenvalues and $E$ - eigenvectors. A solution to equation (13) provides 3 eigenvalues and a matrix of $3 \times 3$ eigenvectors that are referred to the sum of the squares of distances from the fitted plane, whereas eigenvectors provide 3 sets (matrix $E$ columns) of $a, b$ and $c$ values. All is left is to select $a, b$ and $c$ set in relation to the least eigenvalue.

Searching for the algorithms for the calculation of eigenvalues and eigenvectors may be realized in mathematical calculation software (e.g. Matlab). In order to compose an algorithm for plain fitting and edge determination acting in the differently programming interface, a programming module was developed by Python.

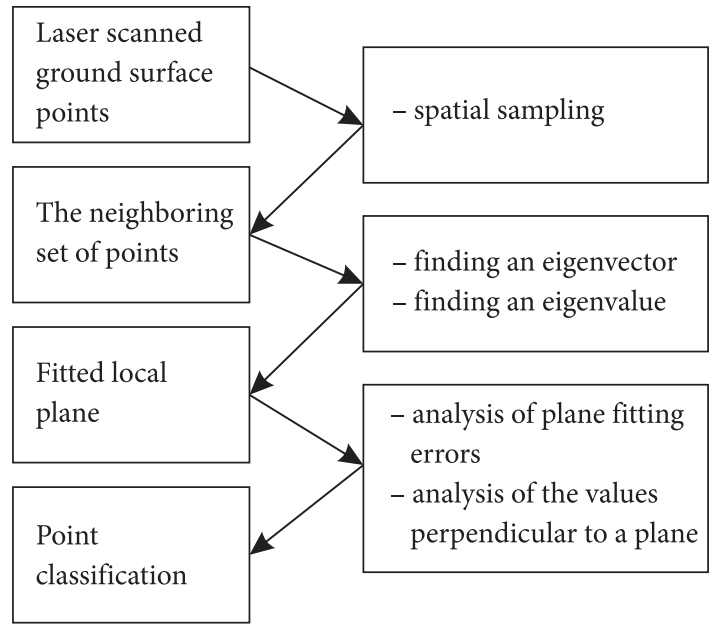

Fig. 1. The algorithm for plane fitting and point classification 
The composed algorithm obtains a direction of a vector vertical to the plane in accordance with the Jacobi method when a normal equation of the plane is $x \cos a+y \cos b+z \cos c-d=0$, where $d$ is the distance of the plain from the coordination start point. Distances from each point to the fitted plane are applied for calculating the average square error. The algorithm checks whether the received true values are not the same in respect of the required precision of calculation. In such a case, the points are situated symmetrically in respect of each other and the plane cannot be fitted.

\section{Experiment}

The extent of the conducted experiment covered 90047 points of height measurement in the territory of 2.3 ha where road reconstruction was simulated by forming a new road structure at a depth of $0.8 \mathrm{~m}$ from the present road surface. Criteria for evaluating the results of the experiment included a decrease in point quantity when filtering according to the proposed algorithm; difference in the volume of land works of the newly designed road when calculating according to the relief model created all height points and filtrated height points.

The values suitable for fitting have been determined during the experiment: the filtering parameter of vicinity (d) and a parameter of fitting an error for the plane (rms). Differences in the volumes of land works have been determined in the tested territory applying valid parameters.

Two tests have been performed applying vicinity distances $d=0.5 \mathrm{~m}$ and $\mathrm{d}=1.5 \mathrm{~m}$. When value $\mathrm{d}=$ $0.5 \mathrm{~m}$ is used, the obtained results make $0 \mathrm{~m}<\mathrm{rms}<$ $0.18 \mathrm{~m}$. When value $\mathrm{d}=1.5 \mathrm{~m}$ is used, the results are $0 \mathrm{~m}<\mathrm{rms}<0.36 \mathrm{~m}$. The received results show that the inaccuracy of applying the plane in the vicinity of the points at $0.5 \mathrm{~m}$ is optimistic and does not allow credibly selecting height points on relief edges and in the vicinity of them (Fig. 2).

When increasing vicinity coverage up to a distance of $1.5 \mathrm{~m}$, the obtained results allow reliably classifying height points according to the average square values of applying the plane. Value rms of $0.05 \mathrm{~m}$ reliably identifies the points of the relief break (Fig. 3).

When a reliable value of vicinity extent and a significant value of plane fitting have been set, the points (rms $<0.05 \mathrm{~m}$ ) approximate to the planes and applied locally are eliminated (filtrated) from the general set of height points. When the above described filter is applied, a set of 90047 height points includes 12982
(Fig. 4) points, i.e. the extent of the set has decreased $7 x$, which increases the speed of software used for designing the road apparently.

The experiment has been mainly aimed at determining if the number of the selected points is sufficient for the preparation of the qualitative relief model dedicated for automatic means of road designing. Moreover, both sets of the points have been transferred to the automatic design system: primary original (90047) and filtrated (12982). Two models of the relief surface have been created accordingly in the automatic design system (model_full and model_filter). As a direct comparison of two surface models does not provide an opportunity of evaluating the significance of difference in volumes (land) for the value of construction works, a typical model of the project on structure reconstruction has been created. As regards the structure reconstruction model, it is admissible that the territory of land works covers a distance of $7 \mathrm{~m}$ from the axis of the present road and is designed by an additional traffic lane in both directions. The depth of land works on the new road structure is $0.8 \mathrm{~m}$.

Differences in the models of the land surface model_full and model_filter are presented in Figure 5. It

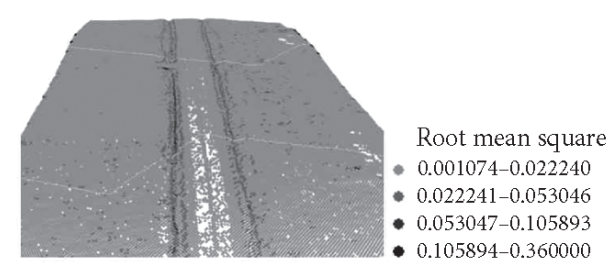

Fig. 2. Rms of plane fitting in the vicinity of the points located at a distance of $0.5 \mathrm{~m}$

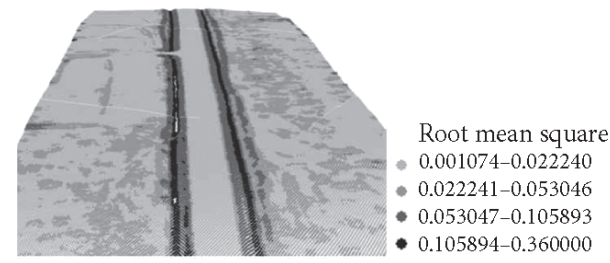

Fig. 3. Rms of plane fitting in the vicinity of the points located at a distance of $1.5 \mathrm{~m}$

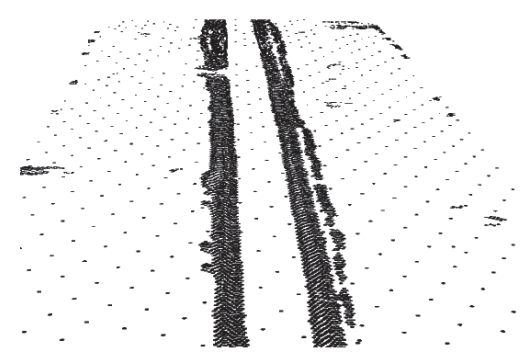

Fig. 4. The points selected for plane fitting under $\mathrm{rms}<0.05 \mathrm{~m}$ 


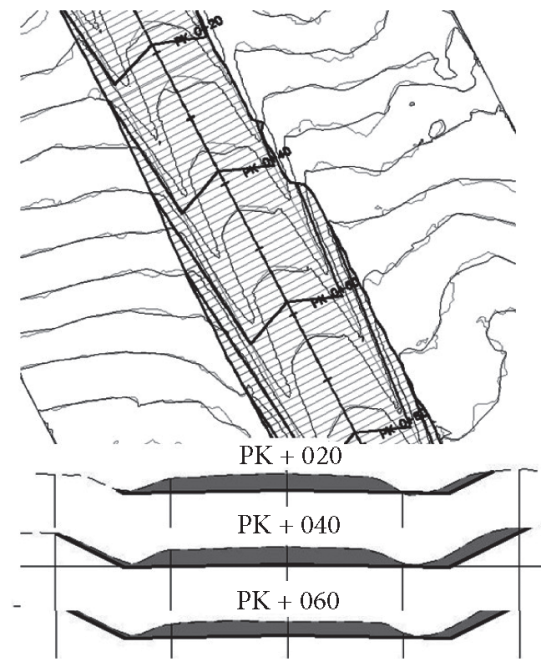

Fig. 5. Fragment of the experimental project on the road structure

is obvious that horizontals shown in Figure 5 at a distance of $0.5 \mathrm{~m}$ and drawn using the first and second model are very close, which shows that the quality of surface imaging under filtrating has not decreased.

A few transverse profiles of the roadbed of the simulated road project have been shown in Figure 5 below; the volumes of land works have been shown and filled in (in case of the model_filter).

When modelling the relief surface according to all scanning points and comparing it to the model for the roadbed of the designed road, the volumes of land works such as poured $-24 \mathrm{~m}^{3}$, excavated $-2342 \mathrm{~m}^{3}$ and balance - $2318 \mathrm{~m}^{3}$ have been obtained. When modelling the relief surface according to the chosen distinctive points and comparing it to the model for the roadbed of the designed road, the following volumes of the works have been received: poured $-24 \mathrm{~m}^{3}$, excavated $-2296 \mathrm{~m}^{3}$ and balance $2272 \mathrm{~m}^{3}$. Differences in the volume of land work, in case of varying relief surfaces, are equal to $46 \mathrm{~m}^{3}$, i.e. the volumes of land works, according to the array of height points thinned by the algorithm, are estimated considering the inaccuracy of $2 \%$ on the basis of the extent of all land works.

According to ST 188710638.06:2004 "Construction of the Roadbed of Transport Roads", the height of the roadbed should be measured referring to the accuracy of $0.05 \mathrm{~m}$. During the experiment on the roadbeds of control transverse profiles, differences in height between the original and filtrated models of the relief have been determined. Height differences between the surfaces have been calculated according to 21 control points (Table 1). The highest value of difference made $0.09 \mathrm{~m}$. The average inaccuracy of the heights of control points makes $0.02 \mathrm{~m}$.
Table 1. Height differences between the surface model_full and model_filter

\begin{tabular}{|c|c|c|c|c|c|c|c|}
\hline Station & $-15 \mathrm{~m}$ & $-10 \mathrm{~m}$ & $-\mathrm{m}$ & $0 \mathrm{~m}$ & $+5 \mathrm{~m}$ & $+10 \mathrm{~m}$ & $+15 \mathrm{~m}$ \\
\hline PK 0 + 20 & 0.09 & 0.03 & 0.00 & 0.05 & 0.00 & 0.06 & 0.01 \\
\hline PK 0 + 40 & 0.02 & 0.00 & 0.00 & 0.06 & 0.00 & 0.00 & 0.01 \\
\hline PK 0 + 60 & 0.02 & 0.00 & 0.00 & 0,06 & 0.00 & 0.00 & 0.02 \\
\hline
\end{tabular}

\section{Conclusions}

The algorithm for the filtration of the array of the point created using laser measurements has been proposed when eliminating redundant points and keeping distinctive points, the array may decrease by $7 x$.

In order to substantiate the experiment, the following parameters have been applied to the algorithm: distance vicinity is equal to $1.5 \mathrm{~m}$ and the limit value of the average square inaccuracy of the points candidates used for the relief model is $0.05 \mathrm{~m}$.

The sufficiency of height points selected by the algorithm for creating the qualitative relief model and its usage when designing the road employing automatic methods have been based on the use of the original and filtrated array of the point for calculating the volume of land works. In case of a common volume of land works, which is $2318 \mathrm{~m}^{3}$, difference in the volume of land works of $46 \mathrm{~m}^{3}$ has been obtained, i.e. the inaccuracy of the volume of land works employing the filtrated point array is equal to $2 \%$.

When redundant height points are thinned according to the proposed algorithm, the average inaccuracy of the heights of the developed relief model is $0.02 \mathrm{~m}$, which proves that the relief model produced using thinned points meets requirements set for a precise height of the roadbed.

\section{References}

Akay, A. E.; Wing, M. G.; Sessions, J. 2014. Estimating sediment reduction cost for low-volume forest roads using a lidarderived high-resolution DEM, The Baltic Journal of Road and Bridge Engineering IX(1): 52-57. http://dx.doi.org/10.3846/bjrbe.2014.07

Briese, C. 2004. Three-dimensional modelling of breaklines from airborne laser scanner data, International Archives of Photogrammetry and Remote Sensing 35(B3): 1097-1102.

Brügelmann, R. 2000. Automatic breakline detection from airborne laser range data, International Archives of Photogrammetry and Remote Sensing 33(B3): 109-114.

Gomes-Pereira, L.; Wicherson, R. 1999. Suitability of laser data for deriving geographical information - a case study in the context of management of fluvial zones, ISPRS Journal of Photogrammetry \& Remote Sensing 54(2-3): 105-114. http://dx.doi.org/10.1016/S0924-2716(99)00007-6 
Kraus, K.; Pfeifer, N. 2001. Advanced DTM generation from LIDAR data, International Archives of Photogrammetry and Remote Sensing XXXIV(3/W4): 23-30.

Mallet, C.; Bretar, F. 2009. Full-waveform topographic lidar: State-of-the-art, ISPRS Journal of Photogrammetry and Remote Sensing 64(1): 1-16.

http://dx.doi.org/10.1016/j.isprsjprs.2008.09.007

Mohamed, M.; Fouad, M. 2014. Simulation-based model for optimizing highways resurfacing operations, The Baltic Journal of Road and Bridge Engineering IX(1): 58-65.

Stankevičius, Ž. 2011. The land surface break lines determination by fitting the local planes, in The $8^{\text {th }}$ International Conference of Environmental Engineering, 19-20 May 2011, Vilnius, Lithuania: Selected papers, 1487-1492.

Stankevičius, Ž.; Kalantaite, A. 2009. LIDAR ground points simplification algorithms array parameter selection, Geodesy and Cartography 35(2): 44-49.

http://dx.doi.org/10.3846/1392-1541.2009.35.44-49

Wang, C.; Tanahashi, H.; Niwa, Y.; Yamamoto, K. 2001. Comparison of local plane fitting methods for range data, in Proc. IEEE Computer Vision and Pattern Recognition, 2001, Hawaii, 1: 663-669.
White, R. A.; Dietterick, B. C.; Mastin, T.; Strohman, R. 2010. Forest roads mapped using LiDAR in steep forested terrain, Remote Sensing 2: 1120-1141.

http://dx.doi.org/10.3390/rs2041120

Žilvinas STANKEVIČIUS received his $\mathrm{PhD}$ in Measurement Engineering from Vilnius Gediminas Technical University in 2000. He earned his diploma in Geodesy in 1993 and MSc in Measurement Engineering in 1995. From 2000 to 2014 he was actively involved in teaching and scientific research. From 1995 to 2000 , he worked at the municipal enterprise "Vilniaus planas" and is currently working at the National Centre of Remote Sensing and Geoinformatics "GIS-Centras"

Žilvinas Stankevičius is the author of more than 20 scientific articles and two textbooks. Research interests include spatial data infrastructures, large scale topographic information management and visualization, sustainable development and spatial analysis in $3 \mathrm{D}$ space. 